\title{
Effects of ring characteristics on the compressive strength and dynamic modulus of elasticity of seven softwood species
}

\author{
Cheng-Jung Lin', Ming-Jer Tsai',*, Chia-Ju \\ Lee $^{2}$, Song-Yung Wang ${ }^{2}$ and Lang-Dong Lin ${ }^{3}$ \\ ${ }^{1}$ Division of Forest Utilization, Taiwan Forestry \\ Research Institute, Taipei, Taiwan \\ 2 School of Forestry and Resource Conservation, \\ College of Bio-Resources and Agriculture, National \\ Taiwan University, Taipei, Taiwan \\ ${ }^{3}$ Department of Forest Products Science, National \\ Chiayi University, Chiayi, Taiwan \\ ${ }^{*}$ Corresponding author. \\ School of Forestry and Resource Conservation, College of \\ Bio-Resources and Agriculture, National Taiwan University, \\ No. 1, Sec. 4, Roosevelt Road, Taipei, 10617 Taiwan \\ Phone: +886-2-33664641, Fax: +886-2-23686335, \\ E-mail: tmj@ntu.edu.tw
}

\begin{abstract}
The effects of ring characteristics on the compressive strength and dynamic modulus of elasticity of seven softwood species in Taiwan were examined. The results revealed good correlation between compressive strength and dynamic modulus of elasticity obtained using an ultrasonic wave technique (correlation coefficient $r=0.77-0.86)$. Overall, compressive strength increased with decreasing ring width parameters and increasing ring density parameters. Ring density was related to compressive strength, but was not the sole factor affecting the wood strength. According to our statistical analysis, compressive strength was affected by various ring characteristics. Relationships between ring characteristics and compressive strength are influenced by the anatomic direction. Results revealed that earlywood density and minimum density in a ring are equally important variables for evaluating the compressive strength of wood.
\end{abstract}

Keywords: compressive strength; dynamic modulus of elasticity; ring characteristics.

\section{Introduction}

Tree ring analysis has been widely applied for many purposes. Bending properties of wood in relation to growth ring characteristics are well established. Alteyrac et al. (2006) identified significant relations among ring width, ring density, microfibril angle, and bending properties of black spruce trees. Wang and Chiu (1993) reported that ring density is significantly related to bending stiffness.

Besides bending strength, compressive strength is important for effective utilization of wood as poles or columns in building components. However, it is difficult to generalize the behavior of woods in transverse compression because of the complex interactions of various anatomic details (Liu and Ross 2005). As a result, the relationships between compressive strength and tree ring features perpendicular to the grain are still not well known.

Scientists have developed non-destructive testing tools for a wide range of applications in the forest products industry in the past 20 years. Ross et al. (1997, 2001) investigated the relationship between compressive strength and stress wave transmission characteristics. Hasegawa et al. (2000) and Hasegawa and Sasaki (2004) reported that ultrasonic velocity was affected in wood under compressive loading. Bucur (1995) investigated the influence of the physical properties of wood on measurements of ultrasonic velocity. Bucur et al. (1999) also pointed out that the parameters of non-destructive evaluation and mechanical properties of wood are greatly influenced by anatomic features.

To understand the effects of ring characteristics on the compressive strength and dynamic modulus of elasticity (DMOE) in longitudinal, radial, and tangential directions of wood, seven domestic softwood species in Taiwan were investigated in this study. An X-ray densitometric technique was applied. Ultrasonic wave testing and compressive tests were performed on small clear specimens to obtain the DMOE and compressive strength. The relationships among ring characteristics, compressive strength, and DMOE are discussed. The results provide basic information for future research, processing, and utilization.

\section{Materials and methods}

\section{Preparation of samples}

Seven local softwoods were selected for this study: Taiwan incense cedar (Calocedrus formosana), Taiwan red cypress (Chamaecyparis formosensis), Japanese cedar (Cryptomeria japonica), Luanta fir (Cunninghamia konishii), China fir (Cunninghamia lanceolata), Taiwania (Taiwania cryptomerioides), and Chinese hemlock (Tsuga chinensis). These woods are common building materials in Taiwan. Preparation of specimens and strips is shown in Figure 1. The data sets consisted of seven species $\times$ three specimens and strips (in three anatomic directions) $\times 30$ replicates. The specimens and strips were conditioned at $20 \pm 3^{\circ} \mathrm{C}$ and $65 \pm 5 \%$ relative humidity until they reached a moisture content of approximately $12 \%$. Only clear specimens without visible defects and polished samples were investigated.

\section{Experimental methods}

Transmitting and receiving transducers were placed by hand using petroleum jelly (Vaseline, Greenwich, CT, USA) as the coupling medium. The ultrasonic velocity and DMOE were measured 


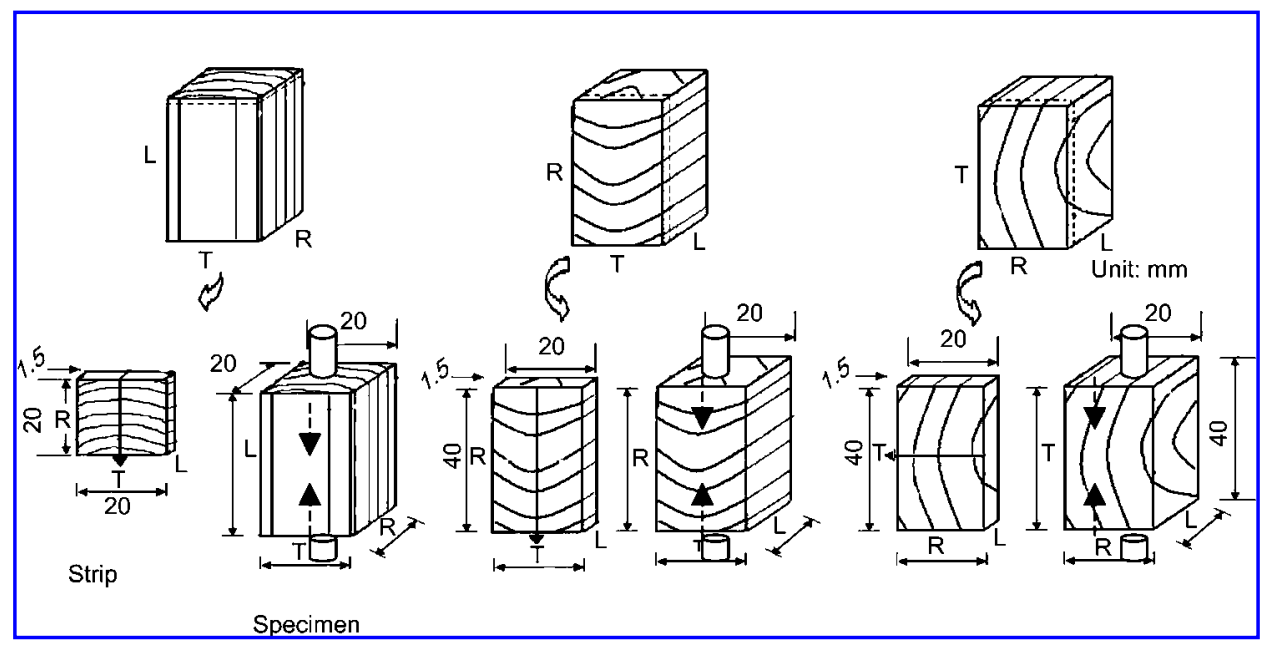

Figure 1 Geometry of wood specimens and strips, and set-up for compressive loading, ultrasonic velocity measurement, and tree ring analysis. L, longitudinal direction; R, radial direction; T, tangential direction; compressive load ( 1 ); ultrasonic transducers ( $\Theta$ ); X-ray scanning direction $(\rightarrow$ ).

and calculated using a PUNDIT meter at a frequency of $150 \mathrm{kHz}$ (CNC Electronic, London, UK) and were calculated as:

$V\left(\mathrm{~m} \mathrm{~s}^{-1}\right)=L / T$

and

$\operatorname{DMOE}(\mathrm{MPa})=V^{2} \times \rho$,

where $V$ is the ultrasonic velocity, $L$ is the length of the specimen, $T$ is the travel time of the pulse through the specimen, and $\rho$ is the density.

Compression tests, parallel to the grain for longitudinal specimens and perpendicular to the grain for radial and tangential specimens, were performed in accordance with CNS standard 453 on a Shimadzu (Japan) UH-10A universal-type testing machine. The specimen is supported near the butt and tip, and a load is applied at the ground line by the moving head of the mechanical testing machine. Deflection curves were obtained from the compression test, and then the ultimate compressive strengths parallel and perpendicular to the grain were calculated from the ultimate load.

The ring characteristics of extracted (distilled water and alcohol-benzene) and conditioned strips were analyzed using a QTRS-01X tree ring analyzer (Quintek Measurement Systems, Knoxville, TN, USA). Strips were scanned in the radial direction.

The standard collimator was $0.038 \mathrm{~mm}$ wide and $1.59 \mathrm{~mm}$ high at the detector. Sample step increments of $0.02 \mathrm{~mm}$ were used. Density was determined based on the relationship with X-ray attenuation (QMS 1999).

Absorption of the X-ray energy is determined in a controlled range and is related to the actual sample density. The equipment was calibrated to the actual sample density. The boundary between earlywood (EW) and latewood (LW) was determined by a comparator, and the location was then converted into a density threshold in the density profile. The ring density boundary (location and density value) was identified using a floating density threshold. Based on the density profiles, the EW and LW boundary was defined in each ring using an average density for maximum and minimum densities in a ring. The tree-ring analysis program was fed with these data. The following characteristics were derived: average ring width, EW width, LW width, ring density, EW density, LW density, maximum density, minimum density, and LW\% in a ring across the sample.

\section{Results and discussion}

\section{Physical and ring characteristics}

Table 1 demonstrates the physical characteristics of the longitudinal, radial, and tangential specimens. Table 2 shows the means of nine ring characteristics for the seven softwood species. The average values of ultrasonic velocity, DMOE, and compressive strength of specimens parallel to the grain were significantly higher than those perpendicular to the grain. The trends for ultrasonic velocity in longitudinal, radial, and tangential specimens are similar to those reported by Mishiro (1996) and Kabir et al. (1997).

\section{Relationships between non-destructive parameters and compressive strength}

Correlation coefficients $(r=0.77-0.86)$ for the relationship between the non-destructive evaluation parameters (ultrasonic velocity and DMOE) and compressive strength

Table 1 Wood density $(D)$, ultrasonic velocity $(v)$, dynamic modulus of elasticity (DMOE), and compressive strength $(\sigma)$ of wood specimens.

\begin{tabular}{lcccr}
\hline Specimen & $\begin{array}{c}\mathrm{D} \\
\left(\mathrm{kg} \mathrm{m}^{-3}\right)\end{array}$ & $\begin{array}{c}v \\
\left(\mathrm{~m} \mathrm{~s}^{-1}\right)\end{array}$ & \multicolumn{1}{c}{$\begin{array}{c}\text { DMOE } \\
(\mathrm{MPa})\end{array}$} & $\begin{array}{c}\sigma \\
(\mathrm{MPa})\end{array}$ \\
\hline Longitudinal & $361.0-685.2$ & $3630.8-4868.7$ & $6765.5-11591.4$ & $33.3-56.4$ \\
Radial & $388.5-648.0$ & $1607.1-1850.1$ & $1270.3-2227.2$ & $3.8-13.2$ \\
Tangential & $403.7-614.5$ & $1158.0-1660.5$ & $543.9-1696.5$ & $3.0-10.4$ \\
\hline
\end{tabular}


Table 2 Average ring characteristics of wood specimens.

\begin{tabular}{lc}
\hline Parameter & Value \\
\hline Ring width $(\mathrm{mm})$ & $2.56-6.96$ \\
$\mathrm{LW}$ width $(\mathrm{mm})$ & $0.52-0.86$ \\
$\mathrm{EW}$ width $(\mathrm{mm})$ & $2.01-6.30$ \\
Ring density $\left(\mathrm{kg} \mathrm{m}^{-3}\right)$ & $397.3-631.8$ \\
$\mathrm{LW}$ density $\left(\mathrm{kg} \mathrm{m}^{-3}\right)$ & $657.4-1016.2$ \\
$\mathrm{EW}$ density $\left(\mathrm{kg} \mathrm{m}^{-3}\right)$ & $274.6-543.8$ \\
Minimum density $\left(\mathrm{kg} \mathrm{m}^{-3}\right)$ & $193.2-452.0$ \\
Maximum density $\left(\mathrm{kg} \mathrm{m}^{-3}\right)$ & $776.4-1183.8$ \\
$\mathrm{LW}(\%)$ & $9.6-21.5$ \\
\hline LW, latewood $\mathrm{EW}$, earlywood &
\end{tabular}

LW, latewood; EW, earlywood.

Table 3 Correlation coefficients for the relationship between wood density $(D)$, ultrasonic velocity $(v)$, dynamic modulus of elasticity (DMOE), and compressive strength $(\sigma)$

\begin{tabular}{|c|c|c|c|}
\hline \multirow[t]{2}{*}{ Variables } & \multicolumn{3}{|c|}{ Correlation coefficient } \\
\hline & Longitudinal & Radial & Tangential \\
\hline$D$ vs. $v$ & $0.57^{\star \star}$ & $0.42^{*}$ & $0.54^{\star \star}$ \\
\hline$D$ vs. DMOE & $0.59^{\star \star}$ & $0.63^{\star \star}$ & $0.50^{\star \star}$ \\
\hline$D$ vs. $\sigma$ & $0.54^{\star \star}$ & $0.59^{\star \star}$ & $0.57^{\star \star}$ \\
\hline$v$ vs. $\sigma$ & $0.86^{\star \star}$ & $0.81^{\star *}$ & $0.77^{\star \star}$ \\
\hline DMOE vs. $\sigma$ & $0.84^{\star \star}$ & $0.83^{\star *}$ & $0.81^{\star \star}$ \\
\hline
\end{tabular}

Significant differences at ${ }^{* *} p<0.01$ and ${ }^{*} p<0.05$.

in the three anatomic directions are shown in Table 3. The strong correlations observed are consistent with the results of Bucur (1995, 1999), Cai et al. (2000), Shaji et al. (2000), and Hasegawa and Sasaki (2004), who concluded that run time or wave velocity is the best method for lumber evaluation.

However, coefficients for relationship between compressive strength and density were poor $(r=0.54-0.59)$. The relevant effect of density on compressive strength may have been masked by ring width parameters and LW\%. Kollmann and Côté (1967) stated that the proportion of LW and the width of the annual rings have a clearly defined effect on the compressive strength. Therefore, the ring density is related to the compressive strength, but it is not the only factor affecting the strength of wood.

\section{Relationships between ring characteristics}

Table 4 shows correlation coefficients for all pairwise comparisons of the nine ring characteristics in the seven softwood species. Based on the results of this study, LW density, LW\%, and minimum density are the most impor- tant parameters determining the overall wood density. Dutilleul et al. (1998) reported that the well-established negative relationship between ring width and wood density was observed only for slow-grown Norway spruce, with no such relationship for fast-grown trees. The authors suggested that the growth rate of a tree is an important parameter. In the present work, the specimens were collected from fast-grown plantation trees, which may explain the lower correlation between ring width and density.

Kennedy (1995), Zhang (1995), and Koga and Zhang (2002) reported that wood density generally tended to decrease with increasing ring width. However, the ring density may vary significantly with various ring characteristics, as demonstrated in this study. Ring density is significantly affected by stem position, tree age, growth trait, genetic factors, environmental conditions of the site, and silvicultural practices (Zobel and van Buijtenen 1989; Dutilleul et al. 1998; Koga and Zhang 2002).

\section{Effects of ring characteristics on the compressive strength and DMOE}

Table 5 shows the correlation coefficients between selected physical properties (DMOE and compressive strength) and ring characteristics. Fitted using linear models, DMOE is positively correlated to ring density in longitudinal specimens, and positively correlated to ring density, EW density, and minimum density, but negatively related to ring width, EW width, and LW width in radial and tangential specimens. Accordingly, only a few of the correlations between DMOE and ring characteristics are indicative of the three principal directions of wood.

There were positive relationships for $\sigma_{\text {long. }}$ (compressive strength for longitudinal specimens) with ring density, EW density, minimum density, and LW\% ( $r=0.54-0.67)$, but negative relationships with ring width and EW width $(r=0.54-0.57)$. There were positive relationships for $\sigma_{\text {rad. }}$ and $\sigma_{\text {tang. }}$ with ring density, EW density, and minimum density $(r=0.57-0.78)$, but negative relationships with ring width, EW width, and LW width $(r=0.30-0.52)$ by linear regression. Based on the above results, there are only a few significant relationships between compressive strength and ring characteristics. On the whole, compressive strength increased with decreasing ring width parameters and increasing ring density parameters.

A stepwise regression procedure was used to determine the most suitable multiple linear regression to pre-

Table 4 Correlation coefficients between ring characteristics.

\begin{tabular}{|c|c|c|c|c|c|c|c|c|}
\hline Variable & $\begin{array}{l}\text { Ring } \\
\text { width }\end{array}$ & $\begin{array}{c}\text { EW } \\
\text { width }\end{array}$ & $\begin{array}{l}\text { LW } \\
\text { width }\end{array}$ & $\begin{array}{c}\text { Ring } \\
\text { density }\end{array}$ & $\begin{array}{c}\text { EW } \\
\text { density }\end{array}$ & $\begin{array}{c}\text { LW } \\
\text { density }\end{array}$ & $\begin{array}{l}\text { Minimum } \\
\text { density }\end{array}$ & $\begin{array}{l}\text { Maximum } \\
\text { density }\end{array}$ \\
\hline EW width & $0.99^{\star \star}$ & & & & & & & \\
\hline LW width & $0.64^{\star \star}$ & $0.55^{\star \star}$ & & & & & & \\
\hline Ring density & $-0.54^{\star \star}$ & $-0.63^{\star \star}$ & $0.24^{\star \star}$ & & & & & \\
\hline EW density & $0.08^{* *}$ & $0.03^{\text {ns }}$ & $0.37^{\star *}$ & $0.20^{\star \star}$ & & & & \\
\hline LW density & $-0.31^{* *}$ & $-0.40^{* *}$ & $0.39^{\star \star}$ & $0.91^{\star \star}$ & $-0.04^{\star \star}$ & & & \\
\hline Minimum density & $-0.35^{\star \star}$ & $-0.43^{\star *}$ & $0.32^{\star *}$ & $0.89^{\star \star}$ & $0.99^{\star \star}$ & $-0.08^{\star \star}$ & & \\
\hline Maximum density & $0.12^{\star \star}$ & $0.06^{\star \star}$ & $0.47^{\star *}$ & $0.25^{\star \star}$ & $0.02^{\text {ns }}$ & $0.96^{\star \star}$ & $-0.03^{\text {ns }}$ & \\
\hline LW\% & $-0.69^{\star *}$ & $-0.75^{\star \star}$ & $0.73^{\star *}$ & $0.90^{\star *}$ & $0.70^{\star \star}$ & $0.32^{\star *}$ & $0.70^{\star \star}$ & $0.36^{\star \star}$ \\
\hline
\end{tabular}

LW, latewood; EW, earlywood. Significant differences at ${ }^{* *} p<0.01$ and ${ }^{*} p<0.05$. ns, $p \geq 0.05$. 
Table 5 Correlation coefficients for relationships between dynamic modulus of elasticity (DMOE) and compressive strength $(\sigma)$ and ring characteristics.

\begin{tabular}{|c|c|c|c|c|c|c|c|c|c|}
\hline Variable & $\begin{array}{l}\text { Ring } \\
\text { width }\end{array}$ & $\begin{array}{c}\text { EW } \\
\text { width }\end{array}$ & $\begin{array}{l}\mathrm{LW} \\
\text { width }\end{array}$ & $\begin{array}{l}\text { Ring } \\
\text { density }\end{array}$ & $\begin{array}{c}\text { EW } \\
\text { density }\end{array}$ & $\begin{array}{l}\text { LW } \\
\text { density }\end{array}$ & $\begin{array}{l}\text { Minimum } \\
\text { density }\end{array}$ & $\begin{array}{c}\text { Maximum } \\
\text { density }\end{array}$ & LW\% \\
\hline \multicolumn{10}{|l|}{ DMOE } \\
\hline Longitudinal & $-0.17^{\mathrm{ns}}$ & $-0.20^{\star *}$ & $0.10^{\text {ns }}$ & $0.59^{\star *}$ & $0.17^{\star}$ & $-0.10^{\mathrm{ns}}$ & $0.10^{\text {ns }}$ & $0.14^{*}$ & $0.14^{*}$ \\
\hline Radial & $-0.52^{\star \star}$ & $-0.50^{* *}$ & $-0.54^{\star *}$ & $0.63^{\star *}$ & $0.69^{\star \star}$ & $0.22^{\star \star}$ & $0.53^{\star \star}$ & $0.10^{\text {ns }}$ & $0.17^{\star \star}$ \\
\hline Tangential & $-0.67^{\star \star}$ & $-0.69^{\star}$ & $-0.51^{\star *}$ & $0.50^{\star \star}$ & $0.39^{\star \star}$ & $0.33^{\star \star}$ & $0.58^{\star \star}$ & $0.10^{\text {ns }}$ & $0.32^{\star \star}$ \\
\hline \multicolumn{10}{|l|}{$\sigma$} \\
\hline Longitudinal & $-0.54^{\star \star}$ & $-0.57^{\star \star}$ & $-0.20^{\star *}$ & $0.54^{\star *}$ & $0.67^{\star \star}$ & $0.22^{\star *}$ & $0.62^{\star \star}$ & $0.20^{\star \star}$ & $0.56^{\star \star}$ \\
\hline Radial & $-0.30^{\star \star}$ & $-0.30^{\star \star}$ & $-0.35^{\star \star}$ & $0.59^{\star \star}$ & $0.76^{\star \star}$ & $-0.20^{\star \star}$ & $0.67^{\star \star}$ & $-0.22^{\star \star}$ & $0.10^{\text {ns }}$ \\
\hline Tangential & $-0.48^{\star \star}$ & $-0.49^{\star *}$ & $-0.52^{\star \star}$ & $0.57^{\star \star}$ & $0.64^{\star \star}$ & $0.22^{\star \star}$ & $0.78^{\star \star}$ & $-0.28^{\star \star}$ & $0.10^{\text {ns }}$ \\
\hline
\end{tabular}

$\mathrm{LW}$, latewood; EW, earlywood. Significant differences at ${ }^{* *} p<0.01$ and ${ }^{*} p<0.05$. ns, $p \geq 0.05$.

dict compressive strength. The following linear regression equations were obtained by the $F$-value test:

$$
\begin{aligned}
\sigma_{\text {long. }}= & 0.019 \times \mathrm{EW} \text { density }+0.005 \times \text { minimum density } \\
& +4.944 \times \mathrm{EW} \text { width }+0.221 \times \mathrm{LW} \%+0.049 \\
& \times \text { ring density }-4.942 \times \text { ring width }+12.185, \\
& r=0.77, F=56.5(p \leq 0.01),
\end{aligned}
$$

$\sigma_{\text {rad. }}=0.029 \times \mathrm{EW}$ density $+0.004 \times$ minimum density

$$
\text { -6.429, } r=0.77, F=145.9(p \leq 0.01)
$$

and

$$
\begin{aligned}
\sigma_{\text {tang. }}= & 0.021 \times \text { minimum density-0.003 } \times \mathrm{EW} \text { density } \\
& +0.025 \times \text { ring density-0.64 } \times \mathrm{LW} \text { width-10.938, } \\
& r=0.87, F=158.7(p \leq 0.01) .
\end{aligned}
$$

These results show that the ring density, EW density, minimum density, ring width, EW width, and LW\% values best predict $\sigma_{\text {long. }}$; the EW density and minimum density values best predict $\sigma_{\text {rad. }}$; and the ring density, EW density, minimum density, and LW width values best predict $\sigma_{\text {tang. }}$. by multiple regression. Accordingly, the effects of ring characteristics on compressive strength in the longitudinal, radial, and tangential directions are quite different. EW density and minimum density in a ring are the most important variables for evaluating compressive strength.

Lin and Chiu (2007) reported that the ring density, EW density, ring width, EW width, and LW\% were critical predictors of compressive strength parallel to the grain. In our study, the EW density and minimum density in a ring were equally important determinants of compressive strength. Kollmann and Côté (1967) stated that compressive stresses cause crumpling of the cell walls in tracheids of coniferous species. Liu and Ross (2005) mentioned that in tangential compression, most of the load is taken by the stronger LW; the weaker EW functions mainly as a lateral support for the LW. In the radial direction, bands between EW and LW carry the same loads, but the LW deforms much less than the EW does. The first failure occurs in the weakest EW band, with subsequent failures occurring in other EW bands and then LW bands as compression progresses. Tsoumis (1991) described how the failure of wood due to axial compression may be traced to the rupture of intercellular layers, cleavage, buckling of cells, and rupture of cell walls. However, stress in transverse compression results in a change in the shape of cell cross-sections and a reduction in the size of cell cavities; with increasing loads, these changes gradually advance from the surface to the interior of the wood.

\section{Conclusions}

Correlation coefficients of $r=0.77-0.86$ were determined between compressive strength and DMOE. Ring density is related to the compressive strength, but is not the sole factor affecting the strength of wood. On the whole, compressive strength increased with decreasing ring width parameters and increasing ring density parameters.

The ring density, EW density, minimum density, LW\%, ring width, and EW width for longitudinal specimens, and the ring density, EW density, minimum density, ring width, EW width, and LW width for radial and tangential specimens were the most important predictors of compressive strength. The effects of ring characteristics on compressive strength are different in the longitudinal, radial, and tangential directions. The EW density and minimum density in a ring were equally important variables for evaluating the compressive strength of wood.

\section{References}

Alteyrac, J., Cloutier, A., Ung, C.H., Zhang, S.Y. (2006) Mechanical properties in relation to selected wood characteristics of black spruce. Wood Fiber Sci. 38:229-237.

Bucur, V. Acoustics of Wood. CRC Press, New York, 1995.

Bucur, V. (1999) Acoustics as a tool for the nondestructive testing of wood. NDT.net 4(11).

Bucur, V., Clement, A., Bitsch, M., Houssment, C. (1999) Acoustic properties of resonance wood and distribution of inorganic components of the cell wall. Holz Roh- Werkst. 57:103104

Cai, Z., Hunt, M.O., Ross, R.J., Soltis, L.A. (2000) Static and vibration modulus of elasticity of salvaged and new joists. For. Prod. J. 50:35-40.

CNS standard (2005) CNS 453, Method of test for compression of wood. Bureau of Standards, Metrology and Inspection, Ministry of Economic Affairs, Taipei, Taiwan.

Dutilleul, P., Herman, M., Avella-Shaw, T. (1998) Growth rate effects on correlations among ring width, wood density, and mean tracheid length in Norway spruce (Picea abies). $\underline{\text { Can. }}$ J. For. Res. 28:56-68. 
Hasegawa, M., Sasaki, Y., Iwata, T. (2000) Acoustoelastic effect of wood III: Effect of applied stresses on the velocity of ultrasonic waves propagating normal to the direction of the applied stress. J. Wood Sci. 46:102-108.

Hasegawa, M., Sasaki, Y. (2004) Acoustoelastic birefringence effect in wood I: Effect of applied stresses on the velocities of ultrasonic shear waves propagating transversely to the stress direction. J. Wood Sci. 50:47-52.

Kabir, M.F., Sidek, H.A.A., Dauck, W.M., Khalid, K. (1997) Effect of moisture content and grain angle on the ultrasonic properties of rubber wood. Holzforschung 51:263-267.

Kennedy, R.W. (1995) Coniferous quality in the future: concerns and strategies. Wood Sci. Technol. 29:321-338.

Koga, S., Zhang, S.Y. (2002) Relationships between wood density and annual growth rate components in balsam fir (Abies balsams). Wood Fiber Sci. 34:146-157.

Kollmann, F.F.P., Côté, W.A. Jr. Principles of Wood Science and Technology I: Solid Wood. Springer-Verlag, New York, 1967.

Lin, C.J., Chiu, C.M. (2007) Relationships among selected wood properties of 20-year-old Taiwania (Taiwania cryptomerioides) trees. J. Wood Sci. 53:61-66.

Liu, J.Y., Ross, R.J. (2005) Relationship between radial compressive modulus of elasticity and shear modulus of wood. Wood Fiber Sci. 37:201-206.

Mishiro, A. (1996) Effect of density on ultrasonic velocity in wood. Mokuzai Gakkaishi 42:887-894.

QMS (1999) QMS Tree Ring Analyzer Model QTRS-01X. User's Guide. Quintek Measurement Systems, Knoxville, TN.
Ross, R.J., DeGroot, R.C., Nelson, W.J., Lebow, P.K. (1997) The relationship between stress wave transmission characteristics and the compressive strength of biologically degraded wood. For. Prod. J. 47:89-93.

Ross, R.J., Pellerin, R.F., Forsman, J.W., Erickson, J.R., Lavinde, J.A. (2001) Relationship between stress wave transmission time and compressive properties of timbers removed from service. General Technical Report FPL-RN-0280. Forest Products Laboratory, Forest Service, US Department of Agriculture, Madison, WI.

Shaji, T., Somayaji, S., Mathews, M.S. (2000) Ultrasonic pulse velocity technique for inspection and evaluation of timber. J. Mater. Civil Eng. 12:180-185.

Tsoumis, G. Science and Technology of Wood - Structure, Properties, Utilization. Van Nostrand Reinhold, New York, 1991.

Wang, S.Y., Chiu, C.M. (1993) Wood properties of Japanese cedar originated by seed and vegetative reproduction in Taiwan VI. Compression and bending properties. Mokuzai Gakkaishii 39:1128-1139.

Zhang, S.Y. (1995) Effect of growth rate on wood specific gravity and selected mechanical properties in individual species from distinct wood categories. Wood Sci. Technol. 29:451465.

Zobel, B.J., van Buijtenen, J.P. Wood Variation: Its Causes and Control. Springer-Verlag, Berlin, 1989.

Received November 15, 2006. Accepted April 2, 2007. 